\title{
Fertility-Related Quality of Life Amongst Married Infertile Females of Lahore
}

\author{
${ }^{1}$ Hira Ashfaq, ${ }^{2}$ Ahmad Naseem, ${ }^{3}$ Shabnum Tariq, ${ }^{4}$ Hina Usman, ${ }^{5}$ Tayyiba Wasim, \\ ${ }^{4}$ Maria Sharif, ${ }^{6}$ Naheed Humayun \\ ${ }^{1}$ Department of Surgery, EME Trust Hospital, Lahore \\ ${ }^{2}$ Department of Medicine, Jinnah Hospital, Lahore \\ ${ }^{3}$ Department of Obstetrics and Gynecology, Lahore General Hospital, Lahore \\ ${ }^{4}$ Department of Public Health and Community Medicine, Shaikh Zayed Medical Complex, Lahore \\ ${ }^{5}$ Department of Obstetrics and Gynecology, Services Institute of Medical Sciences, Lahore \\ ${ }^{6}$ Department of Community Medicine, Red Crescent Medical College, Lahore
}

\begin{abstract}
Introduction: In today's world of science and medicine, assessing ones' quality of life has become a norm. It provides baseline information for future planning in order to elevate quality of life of individuals and communities.

Aims \& Objectives: To assess the quality of life of infertile women and identify factors influencing it.

Place and duration of study: Data was collected from Lahore General Hospital and Services Institute of Medical Sciences, Lahore during 2019.

Material \& Methods: A cross-sectional study was conducted on 260 married, infertile females attending infertility clinics of two tertiary care hospitals of Lahore. 36-items FertiQoL, an Urdu validated version was used to assess the quality of life of females with infertility. It had six subscales and three total scores. Data was analyzed through SPSS version 22.

Results: Mean age of females was found to be $30 \pm 5.23$ years and $85.8 \%$ were not working women. Average duration of infertility was 6.7 years. $61.5 \%$ of females presented with primary infertility. $70.4 \%$ reported positive attitude of their husband towards this infertility while $56.2 \%$ of the participants reported positive attitude of their in-laws as well. $30.8 \%$ of the females rated their health as poor. $31.2 \%$ reported to be dissatisfied with their overall quality of life. In FertiQoL, 'Emotional' subscale showed mean $67 \pm 14$ SD, 'Mind-body' subscale mean $69 \pm 14$ SD, 'Relational' subscale mean $55 \pm$ 14.7 SD, 'Social' subscale mean 66.2 \pm 14.5 SD, 'Treatment Environment' mean $70 \pm 17.5$ SD and 'treatment tolerability' showed mean of $73 \pm 17.2 \mathrm{SD}$. 'Total scaled core score' showed mean of $64.5 \pm 12 \mathrm{SD}$, 'total scaled treatment score' mean of $69.3 \pm 14$ SD and 'total scored FertiQoL score' showed mean of $66 \pm 12$ SD. Significant association between family income and mind body subscale; duration of marriage and treatment tolerability; time till infertility diagnosis and treatment environment was found. While overall FertiQoL score and Family Income was found to be significantly associated.

Conclusion: Overall quality of life of infertile females is not compromised as was thought of except for its association with family income. Sub scales of mind-body, treatment tolerability and treatment environment were found to be associated with family income, duration of marriage and time till infertility diagnosis respectively. Recognition of factors associated with poor quality of life will help in planning strategies to overcome them during infertility treatment.
\end{abstract}

Key words: Fertility, Infertility, Quality of Life, FertiQoL

\section{INTRODUCTION}

$\mathrm{I}$ nfertility by definition is failure to conceive after 1 year of unprotected intercourse amongst heterosexual couples. ${ }^{1}$ It is used synonymously with terms such as sterility, childlessness and subfertility. It can be devastating for those couples who want to have children and can affect both genders equally. ${ }^{2}$ As definition of infertility lacks clarity and uniformity, a systematic review was done in 2011 on defining demographic and epidemiological aspects of infertility. ${ }^{3}$ In a systematic review, 277 demographic and reproductive health surveys data showed infertility prevalence to be highest in South Asia, Sub-Saharan Africa, North Africa/Middle East, Central/Eastern Europe and Central Asia. ${ }^{4}$ Higher prevalence of sexual dysfunction which includes decreased sexual desire, orgasm and satisfaction was found to be 9.5 folds higher in secondary infertile women as compared to primary infertile. $^{5}$

World Health Organization (WHO) defines quality of life (QoL) as an 'individuals' perceptions of their 
position in life in the context of the culture and value systems in which they live and in relation to their goals, expectations, standards and concern'. 6 Infertility influences quality of life of couples especially females. Infertility-related perceptions and responses are huge and they influence QoL of couples in different ways. ${ }^{7}$ Polycystic Ovarian Syndrome (PCOS) with growing incidence is one of the leading causes of infertility now. A significant amount of studies on PCOs and other causes of infertility, showed concerns pointing towards infertility and its' associated behavioral and quality of life issues in our societies. ${ }^{89}$ Infertility related stress, anxiety, depression, psychological and emotional issues are influencing and determining factors of quality of life of couples. ${ }^{10-13}$ Patientreported outcome measures were used to assess infertility-related quality of life in Turkish, Hungarian, Tunisian, Iranian and Taiwanese couples. ${ }^{14-21}$ The Impact of Infertility on the psychological well-being, marital relationships, sexual relationships, and quality of life of Couples was assessed in a systematic review of literature and found to be influenced by infertility. ${ }^{22}$ A comparison between infertile and fertile couples about Quality of Life, sexual satisfaction and marital satisfaction showed difference. ${ }^{23}$ A systematic review in 2013 was done on questionnaires measuring quality of life in infertile couples. ${ }^{24}$ Cross-cultural differences were found in fertility specific quality of life in German, Hungarian and Jordanian couples attending a fertility center. ${ }^{25}$ A study done in Pakistan in 2011 reported psychological consequences of infertility to be huge. ${ }^{26}$

Multiple quality of life assessment tools were developed and validated in different languages over last few decades but a tool comprehensively addressing QoL in infertile couples was still needed. ${ }^{27,28}$ European Society of Human Reproduction and Embryology (ESHRE) and the American Society of Reproductive Medicine (ASRM) jointly did efforts to create the fertility quality of life (FertiQoL) instrument to measure QoL in couples with fertility problems. FertiQoL used same protocol as was used for the development of WHOQOL measure. ${ }^{6}$ FertiQoL is a questionnaire internationally developed to measure fertilityspecific quality of life. It is considered to be a reliable tool and measures impact of fertility problems and their effect on QoL. In total it consists of 36 items and has been translated into 20 different languages. ${ }^{29}$ Limited literature is published from Pakistan so there is a need to generate evidence on quality of life of infertile females. ${ }^{30,31,32}$ The objective of this study was to assess the quality of life of infertile females and identify the factors influencing it.

\section{MATERIAL AND METHODS}

A cross-sectional study was conducted in infertility clinics of two tertiary care teaching hospitals of Lahore. Administrative consent along with ethical clearance from Departmental Ethical Committee was obtained. Total 260 participants (married, infertile females) from 2 centers of Lahore (Lahore General Hospital and Services Institute of Medical Sciences) were included in the study. Sample size was calculated taking expected proportion of quality of life as 0.5 , with 0.05 precision and $95 \%$ confidence level. Females coming for infertility treatment were consecutively selected till the desired sample size was reached in both hospitals. Verbal informed consent was obtained from each participant in presence of witness. FertiQoL, which consists of 36 items that assess core (24 items) and treatment-related Quality of Life (QoL) (10 items) and overall life and physical health (2 items) was used. ${ }^{29}$ The items in the FertiQoL survey were rated on a scale of $0-4$, a higher score means more favorable QoL. It was translated in multiple languages and is available on (http://www.fertiqol.org/). Forms were kept anonymous and their data privacy and confidentiality was maintained by the researchers.

\section{Statistical analysis:}

Statistical analysis was done on SPSS version 22.0. Chi-square, T-test and ANOVA were applied to identify association.

\section{RESULTS}

The mean age of the participants was found to be 30 years which shows that it is the average best-fitted value for the whole sample with a \pm 5.23 standard deviation (SD). Duration of infertility of females had mean of $6.7 \pm 5.02 \mathrm{SD}$. Total family income had mean of 25853.8 with \pm 25564.24 standard deviation and total family members had mean of $4.47 \pm 2.63$ SD. Results showed that out of 260 females, 106 $(40.8 \%)$ had cousin marriages and majority of them (223, 85.8\%) were housewives. Husband's occupation showed that most of them 132 (50.8\%) were doing jobs. Husband's education revealed that $59(22.7 \%)$ were illiterate, $30(11.5 \%)$ had attained education till primary level, $90(34.6 \%)$ had attained education till matriculation, $35(13.5 \%)$ had done intermediate, $39(15.0 \%)$ did graduation and only 7 (2.7\%) had attained higher education. Most of the women i.e, $160(61.5 \%)$ had primary type of 
infertility. $77(29.6 \%)$ of the females reported negative attitude of their husband while negative attitude of in-laws was reported by $114(43.8 \%)$ of the respondents. $80(30.8 \%)$ rated their health as poor and $81(31.2 \%)$ reported to be dissatisfied with their quality of life (Table-1).

\begin{tabular}{|c|c|c|c|}
\hline & & $\begin{array}{c}\text { Frequency } \\
(\mathrm{N}=260)\end{array}$ & $\begin{array}{c}\text { Percent } \\
\% \\
\end{array}$ \\
\hline \multirow{2}{*}{ Cousin marriage } & Yes & 106 & $40.8 \%$ \\
\hline & No & 154 & $59.2 \%$ \\
\hline \multirow[t]{2}{*}{ Working women } & Yes & 37 & $14.2 \%$ \\
\hline & No & 223 & $85.8 \%$ \\
\hline \multirow{5}{*}{$\begin{array}{l}\text { Husband } \\
\text { occupation }\end{array}$} & Job & 132 & $50.8 \%$ \\
\hline & Business & 46 & $17.7 \%$ \\
\hline & Laborer & 78 & $30.0 \%$ \\
\hline & Others & 3 & $1.2 \%$ \\
\hline & Unemployed & 1 & $0.4 \%$ \\
\hline \multirow{6}{*}{$\begin{array}{l}\text { Husband } \\
\text { education }\end{array}$} & Illiterate & 59 & 22.7 \\
\hline & Primary & 30 & 11.5 \\
\hline & Matric & 90 & 34.6 \\
\hline & Intermediate & 35 & 13.5 \\
\hline & Bachelors & 39 & 15.0 \\
\hline & Higher education & 7 & 2.7 \\
\hline \multirow[b]{2}{*}{ Infertility type } & Primary & 160 & $61.5 \%$ \\
\hline & Secondary & 100 & $38.5 \%$ \\
\hline \multirow{2}{*}{ Husband attitude } & Positive & 183 & $70.4 \%$ \\
\hline & Negative & 77 & $29.6 \%$ \\
\hline \multirow{2}{*}{ In-laws attitude } & Positive & 146 & $56.2 \%$ \\
\hline & Negative & 114 & $43.8 \%$ \\
\hline \multirow{5}{*}{$\begin{array}{l}\text { How would you } \\
\text { rate your health? }\end{array}$} & Very poor & 20 & $7.7 \%$ \\
\hline & Poor & 80 & $30.8 \%$ \\
\hline & $\begin{array}{l}\text { Neither good } \\
\text { neither bad }\end{array}$ & 72 & $27.7 \%$ \\
\hline & Good & 70 & $26.9 \%$ \\
\hline & Very good & 18 & $6.9 \%$ \\
\hline \multirow{5}{*}{$\begin{array}{l}\text { Are you satisfied } \\
\text { with your quality } \\
\text { of life? }\end{array}$} & Very dissatisfied & 2 & $0.8 \%$ \\
\hline & Dissatisfied & 81 & $31.2 \%$ \\
\hline & $\begin{array}{l}\text { Neither satisfied } \\
\text { neither dissatisfied }\end{array}$ & 59 & $22.7 \%$ \\
\hline & Satisfied & 107 & $41.2 \%$ \\
\hline & Very satisfied & 11 & $4.2 \%$ \\
\hline
\end{tabular}

Table-1: Socio-demographic characteristics of married infertile females of Lahore

Range along with mean and SD were calculated for total FertiQoL and its subscales. Emotional subscale showed a range of $37-95$ with mean $\pm \mathrm{SD}$ of $67 \pm 14$, Mind-body showed a range of 37-100 with mean \pm SD of $69 \pm 14$, Relational subscale revealed a range of 20-87 with mean \pm SD of $55 \pm 14.7$, Social subscale showed a range of 29-95 with mean \pm SD of $66.2 \pm 14.5$, Environment revealed a range of 2992 with mean \pm SD of $70 \pm 17.5$, Tolerability revealed a range of 25-100 with mean \pm SD of $73 \pm 17.2$. Total scaled core score had range of 38.591 with mean \pm SD of $64.5 \pm 12$, Total scaled treatment score had range of 37.5-95 with mean \pm SD of $69.3 \pm 14$ and Total scored FertiQoL score had range of 41-91 with mean \pm SD of $66 \pm 12$ (Table-2). Variables and subscales showed a significant association between family income and mind-body subscale, duration of marriage and treatment tolerability, time till infertility diagnosis and treatment environment (Table-5). With FertiQoL as dependent variable and age and family income as independent variables inferential analysis was performed. Level of significance was set at $<0.05$. T-test was found to be significant $(0.021)$ for FertiQoL and Family Income (Table-3).

Test of variance (ANOVA) was applied for age, duration of marriage, family income and number of family members and was found to be significant only for family income ( $p$-value $=0.019)$ (Table-4).

\begin{tabular}{|l|c|c|}
\hline Subscales \& Total FertiQoL & $\begin{array}{c}\text { Range } \\
(\mathbf{1 - 1 0 0 )}\end{array}$ & $\begin{array}{c}\text { Mean } \pm \\
\text { SD }\end{array}$ \\
\hline Emotional & $37-95$ & $67 \pm 14$ \\
\hline Mind-body & $37-100$ & $69 \pm 14$ \\
\hline Relational & $20-87$ & $55 \pm 14.7$ \\
\hline Social & $29-95$ & $66.2 \pm 14.5$ \\
\hline Treatment Environment & $29-92$ & $70 \pm 17.5$ \\
\hline Treatment Tolerability & $25-100$ & $73 \pm 17.2$ \\
\hline *Total Scaled Core Score & $38.5-91$ & $64.5 \pm 12$ \\
\hline **Total Scaled Treatment Score & $37.5-95$ & $69.3 \pm 14$ \\
\hline ***Total scaled FertiQoLscore & $41-91$ & $66 \pm 12$ \\
\hline
\end{tabular}

Table-2: FertiQoL and the subscales in married infertile females of Lahore

*total scaled core score $=$ emotional + mind-body + relational + social

$* *$ total scaled treatment $\mathrm{score}=$ treatment environment + treatment tolerability

\begin{tabular}{|c|c|c|c|c|}
\hline \multirow{2}{*}{ Factors } & \multirow{2}{*}{$\begin{array}{c}\text { Categories } \\
\text { of factors }\end{array}$} & Mean & \multicolumn{2}{|c|}{$\begin{array}{c}\text { T-test for equality } \\
\text { of means }\end{array}$} \\
\cline { 3 - 5 } & & & t- statistic & p-value \\
\hline \multirow{2}{*}{$\begin{array}{c}\text { Age } \\
\text { (years) }\end{array}$} & $<\mathbf{2 5}$ & 65.26 & 0.268 & 0.789 \\
\cline { 2 - 3 } & $>\mathbf{2 5 . 1}$ & 65.81 & & \\
\hline $\begin{array}{c}\text { Family } \\
\text { income } \\
\text { (rupees) }\end{array}$ & $<\mathbf{2 5 0 0 0}$ & 64.81 & -2.322 & 0.021 \\
\cline { 2 - 3 } & $>\mathbf{2 5 0 0 1}$ & 68.45 & & \\
\hline
\end{tabular}

Table-3: T-test for age and family income

\begin{tabular}{|l|c|c|}
\hline \multicolumn{1}{|c|}{ Variables } & $\begin{array}{c}\text { t-test } \\
\text { (ANOVA) }\end{array}$ & p-value \\
\hline Age & -1.320 & 0.188 \\
\hline Duration of marriage & 0.22 & 0.983 \\
\hline Family Income & 2.354 & 0.019 \\
\hline Family Members & 1.083 & 0.280 \\
\hline
\end{tabular}

Table-4: Test of Variance (ANOVA) for age, duration of marriage, family income and number of family members 


\begin{tabular}{|c|c|c|c|c|c|c|c|c|c|c|c|c|c|c|c|c|c|c|c|c|c|c|c|c|c|c|c|c|c|c|c|c|c|c|}
\hline \multirow[t]{2}{*}{ Variables } & & \multicolumn{4}{|c|}{ Emotional } & \multirow{2}{*}{\begin{tabular}{|c|}
$\begin{array}{c}\mathbf{P} \\
\text { value }\end{array}$ \\
\\
\end{tabular}} & \multicolumn{4}{|c|}{ Mind-body } & \multirow{2}{*}{\begin{tabular}{|c|}
$\begin{array}{c}\mathbf{P} \\
\text { value }\end{array}$ \\
\end{tabular}} & \multicolumn{4}{|c|}{ Relational } & \multirow{2}{*}{\begin{tabular}{|c|}
$\begin{array}{c}\mathbf{P} \\
\text { value }\end{array}$ \\
\\
\end{tabular}} & \multicolumn{4}{|c|}{ Social } & \begin{tabular}{|c|c}
$\mathbf{P}$ \\
value
\end{tabular} & \multicolumn{4}{|c|}{\begin{tabular}{|l|c|} 
Treatment & $\mathbf{P}$ \\
invironment & value \\
\end{tabular}} & \multicolumn{4}{|c|}{$\begin{array}{c}\text { Treatment } \\
\text { Tolerability }\end{array}$} & \begin{tabular}{|c|c|}
$\mathbf{P}$ & \\
value & \\
\end{tabular} & \multicolumn{2}{|c|}{$\begin{array}{c}\text { Total } \\
\text { Fertiqol }\end{array}$} & \multicolumn{2}{|c|}{\begin{tabular}{|c|}
$\mathbf{P}$ \\
value
\end{tabular}} \\
\hline & & $\mathrm{P}$ & A & $\mathrm{G}$ & $\mathrm{E}$ & & $\mathrm{P}$ & A & $\mathrm{G}$ & $\mathrm{E}$ & & $\mathrm{P}$ & A & $\mathrm{G}$ & $\mathrm{E}$ & & $\mathrm{P}$ & $\mathrm{A}$ & G & $\mathrm{E}$ & \multirow{4}{*}{0.44} & $\mathrm{P}$ & A & \begin{tabular}{l|l}
$\mathrm{G}$ & $\mathrm{E}$ \\
\end{tabular} & \multirow{4}{*}{0.56} & \begin{tabular}{|l|}
$\mathrm{P}$ \\
\end{tabular} & $\mathrm{A}$ & \begin{tabular}{l|l}
$\mathrm{G}$ & $\mathrm{E}$ \\
\end{tabular} & & & $\mathrm{PA}$ & $\mathrm{G}$ & $\mathrm{E}$ & \\
\hline \multirow{3}{*}{$\begin{array}{c}\text { Duration } \\
\text { of } \\
\text { marriage } \\
\text { (years) }\end{array}$} & $1-10$ & 0 & \begin{tabular}{l|l}
35 & 1. \\
\end{tabular} & & 52 & \multirow{3}{*}{0.75} & 0 & 24 & 139 & 56 & & 2 & 94 & 104 & 19 & & 0 & 35 & 125 & 59 & & 0 & 51 & \begin{tabular}{l|l}
9177 \\
\end{tabular} & & \begin{tabular}{|l|l}
1 & 3 \\
\end{tabular} & 31 & \begin{tabular}{l|l}
97 & 9 \\
\end{tabular} & & & $0 \mid 261$ & & \multirow{3}{*}{\multicolumn{2}{|c|}{0.627}} \\
\hline & $11-20$ & 0 & \begin{tabular}{l|l}
8 & 1 \\
\end{tabular} & 17 & 8 & & 0 & 4 & 18 & 11 & & 0 & 18 & 14 & 1 & & 0 & 9 & 15 & 9 & & 0 & 6 & \begin{tabular}{l|l}
18 & 9 \\
\end{tabular} & & \begin{tabular}{|l|}
0 \\
\end{tabular} & 3 & \begin{tabular}{l|l}
18 & 11 \\
\end{tabular} & & & \begin{tabular}{l|l|l}
0 & 6 & 1
\end{tabular} & 189 & & \\
\hline & 21-30 & 0 & 2 & 4 & 2 & & 0 & 1 & 7 & 0 & & 0 & 3 & 5 & 0 & & 0 & 2 & 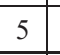 & 1 & & 0 & 3 & \begin{tabular}{|l|l}
3 & 2 \\
\end{tabular} & & 1 & 0 & \begin{tabular}{l|l}
5 & 2 \\
\end{tabular} & 2 & & \begin{tabular}{ll|l}
02 & \\
\end{tabular} & \begin{tabular}{l|l}
5 & 1 \\
\end{tabular} & & \\
\hline \multirow{2}{*}{$\begin{array}{l}\text { Family } \\
\text { Income } \\
\text { (rupees) }\end{array}$} & $1-25000$ & 0 & \begin{tabular}{l|l}
34 & 11
\end{tabular} & & 37 & \multirow{2}{*}{0.15} & 0 & 22 & 124 & 34 & \multirow[b]{2}{*}{0.00} & 2 & 82 & 83 & 13 & \multirow[b]{2}{*}{0.69} & 0 & 32 & 107 & 41 & \multirow[b]{2}{*}{0.31} & 0 & 48 & \begin{tabular}{l|l|l}
71 & 61
\end{tabular} & \multirow{2}{*}{0.08} & 12 & 27 & \begin{tabular}{l|l}
87 & 6 \\
\end{tabular} & & & \begin{tabular}{l|l|l}
0 & 25 & 1 \\
\end{tabular} & \begin{tabular}{l|l}
113 & 4 \\
\end{tabular} & 12 & \\
\hline & \begin{tabular}{|l|}
$26000-$ \\
250000 \\
\end{tabular} & 0 & 114 & 44 & 25 & & 0 & 7 & 40 & 33 & & 0 & 33 & 40 & 7 & & 0 & 14 & 38 & 28 & & 0 & 12 & 4127 & & \begin{tabular}{|l|}
1 \\
\end{tabular} & 7 & 333 & & $1 8 \longdiv { 0 }$ & \begin{tabular}{l|l|l}
0 & 9 & 4
\end{tabular} & 442 & 27 & \\
\hline & $1-8$ & 0 & \begin{tabular}{l|l}
39 & 1.
\end{tabular} & & 54 & & 0 & 23 & 146 & 60 & & 2 & 101 & 107 & 19 & & 0 & 39 & 132 & 58 & & 0 & 56 & \begin{tabular}{l|l|}
95 & 78 \\
\end{tabular} & & 23 & \begin{tabular}{l|l}
30 & 1 \\
\end{tabular} & 1069 & & & $\begin{array}{lll}0 & 30 & 1\end{array}$ & 1396 & 50 & \\
\hline & $9-16$ & 0 & \begin{tabular}{l|l}
6 & 1 \\
\end{tabular} & 13 & 8 & 0.49 & 0 & 5 & 15 & 7 & 0.46 & \begin{tabular}{|l|}
0 \\
\end{tabular} & 13 & 13 & 1 & 0.62 & 0 & 7 & 12 & 8 & 0.31 & 0 & 4 & \begin{tabular}{l|l}
17 & 6 \\
\end{tabular} & 0.03 & \begin{tabular}{|l|}
0 \\
\end{tabular} & 3 & \begin{tabular}{l|l}
14 & 11 \\
\end{tabular} & & 530 & \begin{tabular}{ll|l}
0 & 4 & 1 \\
\end{tabular} & \begin{tabular}{l|l}
16 & 7 \\
\end{tabular} & & .618 \\
\hline & $17-24$ & 0 & 0 & 3 & 0 & & 0 & 0 & 3 & 0 & & 0 & 0 & 3 & 0 & & 0 & 0 & 1 & 2 & & 0 & 0 & \begin{tabular}{l|l}
0 & 3 \\
\end{tabular} & & 0 & 0 & \begin{tabular}{l|l}
0 & 3 \\
\end{tabular} & 3 & & 01 & 2 & 3 & \\
\hline & Positive & 0 & & & 39 & & 0 & 18 & 123 & 42 & & 1 & 88 & 81 & 13 & & 0 & 30 & 106 & 47 & & 0 & 47 & 8056 & & \begin{tabular}{|l|l|}
2 & 2 \\
\end{tabular} & 23 & \begin{tabular}{l|l}
83 & 7 \\
\end{tabular} & & & $\begin{array}{lll}0 & 24 & 1\end{array}$ & 1174 & & \\
\hline & Negative & 0 & & 41 & 23 & & 0 & 11 & 41 & 25 & & 1 & 27 & 42 & 7 & & 0 & 16 & \begin{tabular}{l|l}
39 \\
\end{tabular} & 22 & & 0 & 13 & & & \begin{tabular}{|l|l}
0 & 1 \\
\end{tabular} & 11 & \begin{tabular}{l|l}
372 \\
\end{tabular} & & & & \begin{tabular}{l|l}
402 \\
\end{tabular} & & \\
\hline
\end{tabular}

Table-5: Association of socio-demographic variables with sub-scales \& total FertiQoL score

\section{DISCUSSION}

Quality of life related to infertility and factors influencing it were identified in current research. The results of this study showed mean age of mothers at thirty years while majority was housewives. Average duration of infertility was 6.7 years. So on average they were in early marriage phase, staying at home and facing infertility issue for a significant period of time. Most of the women had primary type of infertility. These findings are close to a study findings done in Karachi in $2016 .{ }^{33}$ The reason being females belonging to same socioeconomic class and an urban setting where there is better awareness and families are openminded.

Reproduction is an essential human desire and infertility can manifest itself as stress, anxiety, depression, low self-esteem and declined sexual satisfaction. In our study majority of them rated their health as poor because of infertility and most of them were dissatisfied with their quality of life. In a systematic review, infertility was found to affect couples showing infertility's negative effect on sexual relationship and psychological well-being of couples, but the effect on quality of life and marital relationships was not found. ${ }^{22}$ In our study, total FertiQoL measured inconclusive effect on quality of life but subscales showed a variable response.

Test of variance (ANOVA) was applied for age, duration of marriage, family income and number of family members. It was found to be significant only for family income ( $p$-value $=0.019)$. Low income couples and less than 10 years of married life were found to face lower social subscale score in FertiQoL in a recent Turkish study. ${ }^{15}$ In our study, majority females reported positive attitude of their husband and in-laws towards their infertility issue. This was contradictory to findings from researches done in developing countries in previous decades but similar to latest research on infertility associated behaviors. $^{34}$

A study from Karachi reported a lower mean for all subscales of FertiQoL as compared to our findings. ${ }^{33}$ Our study's total FertiQoL score mean 66 was higher than this. Majority (30.8\%) of the women included in our study rated their health as poor. $31.2 \%$ were dissatisfied with their quality of life and relational subscale which refers to fertilityspecific issues experienced within the couple relationship had mean \pm SD of $55 \pm 14$.7. In Pakistan second marriage is considered if a woman does not bear child in early years of marriage this stress negatively effects their relationship with husband and his family and also effects physical and mental well-being of herself. Treatment tolerability which effectively measures physical and mental well-being and disruption of daily routine due to infertility treatment was found to be significant in this study. Treatment environment scale which assesses the positive environment provided by medical staff during infertility treatment showed a positive association with time till infertility. Results of another study showed that the score of subscales was higher in women with secondary type of infertility meaning a better quality of life. Duration of infertility was also found to be an important factor adversely affecting the quality of life. Higher education status of females was found to be associated with better QoL. ${ }^{24}$

It has been shown that lower income, worsened spousal relationship, infertility related perceptions, pressuring oneself or spouse due to infertility, and strong desire for children are significantly associated with a poor quality of life. ${ }^{7}$ Our study also showed that family income adversely effects total fertiQoL score but other factors did not show a conclusive influence. 
Self-esteem scores were lower in the couples with longer infertility duration. Women are found to be more affected by infertility as compared to men and twelve percent of the women seeking infertility treatment had poor quality of life. Reason for this may be the natural desire of females to bear children. Women reported about more depressive symptoms and poorer quality of life than men. Both in men and women, the higher depression level correlated with lower level of quality of life. Moreover, the presence of more depressive symptoms in women was related to men's poorer quality of life. Women are considered weak psychologically so these findings support this assumption. ${ }^{10-13}$

Infertile couples have to face a wide range of psychological influences so there arises the need for psychological support and counseling of infertile couples. ${ }^{34}$

This was a cross-sectional study focusing on females due to convenience of their presence in infertility clinics as compared to men. A couple based approach may be better for future studies so both can give an insight into quality of life and its subscales. This study provides an comprehensive evaluation of fertility related quality of life in different aspects of infertile women.

\section{CONCLUSION}

It is concluded that Quality of Life in married infertile women is compromised and is influenced by low family income on the whole but Sub scales of mind-body, treatment tolerability and treatment environment are associated with family income, duration of marriage and time till infertility diagnosis respectively. These factors can be addressed to improve quality of life in these subscales/dimensions/ Measures such as counseling or psychotherapy need to be incorporated in the conventional treatment so as to improve Quality of Life of infertile couples.

\section{REFERENCES}

1. Tanha FD, Mohseni M, Ghajarzadeh M. Sexual function in women with primary and secondary infertility in comparison with controls. International journal of impotence research. 2014; 26(4):132.

2. Mascarenhas MN, Cheung H, Mathers CD, Stevens GA. Measuring infertility in populations: constructing a standard definition for use with demographic and reproductive health surveys. Population health metrics. 2012; 10(1):17.

3. Gurunath S, Pandian Z, Anderson RA, Bhattacharya S. Defining infertility - a systematic review of prevalence studies. Human reproduction update. 2011; 17(5):575-88.
4. Mascarenhas MN, Flaxman SR, Boerma $\mathrm{T}$, Vanderpoel S, Stevens GA. National, regional, and global trends in infertility prevalence since 1990: a systematic analysis of 277 health surveys. PLoS medicine. 2012; 9(12):e1001356.

5. Keskin U, Coksuer H, Gungor S, Ercan CM, Karasahin KE, Baser I. Differences in prevalence of sexual dysfunction between primary and secondary infertile women. Fertility and sterility. 2011; 96(5):1213-7.

6. Group W. The World Health Organization quality of life assessment (WHOQOL): position paper from the World Health Organization. Social science \& medicine. 1995; 41(10):1403-9.

7. Lau JT, Wang Q, Cheng Y, Kim JH, Yang X, Tsui HY. Infertility-related perceptions and responses and their associations with quality of life among rural chinese infertile couples. Journal of sex \& marital therapy. 2008; 34(3):248-67.

8. Elsenbruch S, Hahn S, Kowalsky D, Offner AH, Schedlowski M, Mann K, et al. Quality of life, psychosocial well-being, and sexual satisfaction in women with polycystic ovary syndrome. The Journal of clinical endocrinology and metabolism. 2003; 88(12):5801-7.

9. McCook JG, Reame NE, Thatcher SS. Health-related quality of life issues in women with polycystic ovary syndrome. Journal of obstetric, gynecologic, and neonatal nursing : JOGNN. 2005; 34(1):12-20.

10. Newton CR, Sherrard W, Glavac I. The Fertility Problem Inventory: measuring perceived infertilityrelated stress. Fertil Steril. 1999; 72(1):54-62.

11. Nicoloro-SantaBarbara JM, Lobel M, Bocca S, Stelling JR, Pastore LM. Psychological and emotional concomitants of infertility diagnosis in women with diminished ovarian reserve or anatomical cause of infertility. Fertil Steril. 2017; 108(1):161-7.

12. Yusuf L. Depression, anxiety and stress among female patients of infertility; A case control study. Pakistan journal of medical sciences. 2016; 32(6):1340-3.

13. Keramat A, Masoomi SZ, Mousavi SA, Poorolajal J, Shobeiri F, Hazavhei SM. Quality of life and its related factors in infertile couples. Journal of research in health sciences. 2014; 14(1):57-63.

14. Kitchen H, Aldhouse N, Trigg A, Palencia R, Mitchell S. A review of patient-reported outcome measures to assess female infertility-related quality of life. Health and quality of life outcomes. 2017; 15(1):86.

15. Goker A, Yanikkerem E, Birge O, Kuscu NK. Quality of life in Turkish infertile couples and related factors. Human fertility (Cambridge, England). 2017:1-9.

16. Crawford NM, Hoff HS, Mersereau JE. Infertile women who screen positive for depression are less likely to initiate fertility treatments. Human reproduction (Oxford, England). 2017; 32(3):582-7. 
17. Aliyeh G, Laya F. Quality of life and its correlates among a group of infertile Iranian women. Medical science monitor : international medical journal of experimental and clinical research. 2007; 13(7):Cr313-7.

18. Cserepes RE, Bugan A. [Impact of depressive symptomatology in Hungarian infertile couples]. Psychiatria Hungarica : A Magyar Pszichiatriai Tarsasag tudomanyos folyoirata. 2015; 30(1):50-9.

19. Cserepes RE, Korosi T, Bugan A. [Characteristics of infertility-specific quality of life in Hungarian couples]. Orvosi hetilap. 2014; 155(20):783-8.

20. El Kissi Y, Amamou B, Hidar S, Ayoubi Idrissi K, Khairi H, Ali BB. Quality of life of infertile Tunisian couples and differences according to gender. International journal of gynaecology and obstetrics: the official organ of the International Federation of Gynaecology and Obstetrics. 2014; 125(2):134-7.

21. Hsu PY, Lin MW, Hwang JL, Lee MS, Wu MH. The fertility quality of life (FertiQoL) questionnaire in Taiwanese infertile couples. Taiwanese journal of obstetrics \& gynecology. 2013; 52(2):204-9.

22. Luk BH, Loke AY. The Impact of Infertility on the Psychological Well-Being, Marital Relationships, Sexual Relationships, and Quality of Life of Couples: A Systematic Review. J Sex Marital Ther. 2015; 41(6):610-25.

23. Masoumi SZ, Garousian M, Khani S, Oliaei SR, Shayan A. Comparison of Quality of Life, Sexual Satisfaction and Marital Satisfaction between Fertile and Infertile Couples. International journal of fertility \& sterility. 2016; 10(3):290-6.

24. Mousavi SA, Masoumi SZ, Keramat A, Pooralajal J, Shobeiri F. Assessment of questionnaires measuring quality of life in infertile couples: a systematic review. Journal of reproduction \& infertility. 2013; 14(3):110-9.

25. Sexty RE, Hamadneh J, Rosner S, Strowitzki T, Ditzen B, Toth B, et al. Cross-cultural comparison of fertility specific quality of life in German, Hungarian and Jordanian couples attending a fertility center. Health and quality of life outcomes. 2016; 14:27.

26. Sultan S, Tahir A. Psychological consequences of infertility. Hellenic J Psychol. 2011; 8:229-47.

27. Boivin J, Takefman J, Braverman A. The fertility quality of life (FertiQoL) tool: development and general psychometric properties. Fertility and sterility. 2011; 96(2):409-15. e3.

28. Mousavi SA, Masoumi SZ, Keramat A, Pooralajal J, Shobeiri F. Assessment of questionnaires measuring quality of life in infertile couples: a systematic review. Journal of reproduction \& infertility. 2013; 14(3):110.

29. Boivin J, Takefman J, Braverman A. The fertility quality of life (FertiQoL) tool: development and general psychometric properties. Human Reproduction. 2011; 26(8):2084-91.

30. Abbasi S, Kousar R. The fertility quality of life (FertiQol) questionnaire in Pakistani infertile women. 2016.
31. Hassan S-U-N, Siddiqui S, Friedman BD. Health Status and Quality of Life of Women Seeking Infertility Treatments in Baluchistan, Pakistan. The British Journal of Social Work. 2019.

32. HI VARTF, HI VARTUK, Jawad F, Qureshi H, Hameed K, Mehmood K, et al. The Journal of Bahria University Medical and Dental College Karachi, Pakistan.

33. Abbasi S, Kousar R. The fertility quality of life (FertiQol) questionnaire in Pakistani infertile women. Journal of Bahria University Medical and Dental College. 2016; 6(3):4-.

34. Zarif Golbar Yazdi H, Aghamohammadian Sharbaf $\mathrm{H}$, Kareshki H, Amirian M. Psychosocial Consequences of Female Infertility in Iran: A MetaAnalysis. Front Psychiatry. 2020; 11:518961.

\section{The Authors:}

Dr. Hira Ashfaq

House Officer,

Department of Surgery,

EME Trust Hospital, Lahore.

Dr. Ahmad Naseem

House Officer,

Department of Medicine,

Jinnah Hospital, Lahore.

Dr. Shabnum Tariq

Associate Professor,

Department of Obstetrics and Gynecology,

Lahore General Hospital.

Dr. Hina Usman

Visiting Faculty Instructor,

Dept. of Public Health and Community Medicine,

Shaikh Zayed Medical Complex, Lahore.

Prof. Tayyiba Wasim

Department of Obstetrics and Gynecology,

Services Institute of Medical Sciences, Lahore.

Maria Sharif

Biostatistician,

Dept. of Public Health and Community Medicine,

Shaikh Zayed Medical Complex, Lahore.

Prof. Naheed Humayun

Head, Department of Community Medicine,

Red Crescent Medical College, Lahore

\section{Corresponding Author:}

Dr. Ahmad Naseem

House Officer,

Department of Medicine,

Jinnah Hospital, Lahore.

E-mail: ahmad.naseem3344@gmail.com 